\title{
Corpo e gênero nas práticas inclusivas de Ginástica Para Todos na Educação Física Escolar
}

\author{
Body and gender in inclusive practices of Gymnastics for All in Physical Education at School \\ Cuerpo y gênero en las prácticas inclusivas de Gimnasia para Todos en Educación Física Escolar
}

Dayane da Silva Oliveira

Pontifica Universidade Católica de Goiás, Brasil

dayane.65@live.com

(iD https://orcid.org/0000-0003-3807-1771

Leonardo Mercês de Oliveira

Pontifica Universidade Católica de Goiás, Brasil

leo-m-oliveira@hotmail.com

Taynara Reges Cardoso

Pontifica Universidade Católica de Goiás, Brasil

taynara741@hotmail.com

(iD https://orcid.org/0000-0002-9926-4078

\author{
Thiago Camargo Iwamoto \\ Pontifica Universidade Católica de Goiás, Brasil \\ thiagoiwamoto@outlook.com \\ (iD https://orcid.org/0000-0002-1509-6047
}

\section{Resumo:}

O objetivo desse ensaio teórico é refletir e analisar as práticas de inclusão que permeiam a Ginástica para Todos (GPT) na Educação Física Escolar, atentando-se às relações sociais de corpo e gênero. A constituição da inclusão ao longo do processo histórico, desvela uma cultura de exclusão/segregação com estereótipos e rotulações que se expressam nos corpos e nas questões de gênero, e traduzem uma representatividade mascarada por desigualdades sociais e culturais. Por suas características constitutivas, a GPT pode elucidar sujeitos que lutam, resistem e se colocam frente aos estereótipos e às desigualdades de corpos e gênero, criando oportunidades para interação, sociabilidade e inclusão. A GPT possibilita experiências com maior liberdade de movimento, de composição e inclusão das diferenças. Por fim, a GPT se apresenta como uma excelente alternativa para a abordagem de incluir os corpos e gêneros na Educação Física Escolar.

PalaVras-chaVe: Educação Física Escolar, Ginástica para Todos, Inclusão, Corpo, Gênero.

\begin{abstract}
:
The article aims to reflect and analyze the process of inclusion practices that permeate Gymnastics for All in Physical Education at school, paying attention to the social relations of body and gender. The methodology follows the perspective of a narrative review, using sources that discuss Gymnastics for All, inclusion, the body, and gender. The constitution of inclusion throughout the historical process reveals a culture of exclusion/segregation present in humanity. The numerous stereotypes and labels that are present in the image of the body itself reflect a pseudo representativeness that is masked by social/cultural influences. As well as other content applied in Physical Education at school, Gymnastics for All has the role of elucidating subjects who struggle, resist and face difficulties in a selective and hegemonic context, providing participants with an integration, interaction, and sociability, without distinction that is appropriate for the bodies of men and women. This practice makes experience possible without reinforcing the movements that are instituted by society according to gender. Finally, GPT presents itself as an excellent alternative to the approach of including bodies and genders in Physical Education at School.
\end{abstract}

KEYwORDS: Physical Education at school, Gymnastics for All, Inclusion, Body, Gender.

\section{Recepción: 31 Julio 2020 | Aprobación: 15 Marzo 2021| Publicación: 01 Abril 2021}




\section{Resumen:}

El objetivo de este ensayo teórico es reflexionar y analizar las prácticas de inclusión que permean la Gimnasia para Todos (GPT) en la Educación Física Escolar que atentan las relaciones sociales del cuerpo y género. La constitución de la inclusión a lo largo del proceso histórico, devela una cultura de exclusión/segregación con estereotipos y rotulaciones que se expresan en nuestros cuerpos y en las cuestiones de género, y traducen una representatividad enmascarada por desigualdades sociales y culturales. Por sus características constitutivas, la GPT puede dilucidar sujetos que luchan, resisten y se colocan frente a los estereotipos y a las desigualdades de cuerpos y género, creando oportunidades para interacción, sociabilidades e inclusión. GPT posibilita las experiencias con mayor libertad de movimiento, de composición e inclusión de las diferencias. Finalmente, la GPT se presenta como una excelente alternativa para el abordaje que incluye los cuerpos y géneros en la Educación Física Escolar.

Palabras clave: Educación Física Escolar, Gimnasia para Todos, Inclusión, Cuerpo, Género.

\section{INTRODUÇÃO}

A Ginástica para Todos (GPT), conhecida anteriormente como Ginástica Geral (GG), tem em suas características uma dinâmica própria, não instituindo limites estreitos e rígidos para a prática. Sua maior característica está na riqueza de privilegiar todas as possibilidades e formas de trabalho, através de propostas, estilos e tendências que são influenciados por diversos fatores, valores e símbolos culturais. Sua prática é considerada plural devido às múltiplas influências que compõem essa modalidade, sobretudo para a contribuição e integração de todas as pessoas que praticam a GPT (Souza, 1997).

De acordo com Fátima e Ugaya (2016) incorporamos todas as dimensões enquanto vivemos e movemos, seja cultural e/ou historicamente. O movimento humano, como a GPT, é um sistema de comunicação, linguagens e expressões, sendo considerada como uma forma de manifestação cultural, mas que, infelizmente, ainda carrega dicotomias, preconceitos e construções ideológicas no âmbito das práticas pedagógicas. É identificado ideias estereotipadas na sociedade que reforça ações excludentes para e com determinados grupo de pessoas. Pensando na prática, contemporânea e inclusiva, reforçamos o movimento ressignificado através da conexão com valores culturais, históricos e sociais, relacionados às diferentes identidades.

É imprescindível conceber que a sociedade ainda está consolidada em um processo enraizado de comportamentos característicos de cada categoria de gênero, classe, etnicidade, estética e estilo de vida. Alinhadas as oportunidades e acessibilidades, essas categorias conseguem direta e indiretamente controlar e normatizar esses comportamentos baseados em produtos originados da e na cultura, tal como os estereótipos e estigmas (Lanz, 2015).

Consideramos, de forma inicial, que ainda se vê regras e normas na ginástica carregadas de preconceito e discriminação com os corpos, em específico os movimentos e expressões daqueles que não se enquadram em certos padrões estéticos e de gênero. Logo, nos intriga se realmente a GPT consegue transpor essas barreiras, uma vez que todos esses elementos são observados durante as práticas dessa ginástica. Devido à natureza da modalidade, particularmente por ser um tipo de ginástica demonstrativa e com intuito de não excluir as pessoas, entendemos que as questões de corpo e gênero são respeitadas durante todos os momentos (Domingues, \& Tsukamoto, 2021), não havendo uma dicotomização dos corpos e sujeitos. Assim, a prática de GPT está alinhada a uma ideia de flexibilização, não fixando dispositivos binários que reforçam um olhar inteligível entre sexo, gênero e desejo (Butler, 2003).

Lamentavelmente, as práticas corporais ainda se amparam no determinismo biológico binário vigente na sociedade ocidental, como reforçado por Miskolci (2007). Características como agressividade, força, velocidade e agilidade fazem referência aos meninos e, esse alinhamento condiz com as relações sociais que são postas a eles desde o nascimento e que são "alimentadas" ao longo da vida. Essas caracterizações estão equiparadas a um pré-discurso existente que define os comportamentos e funções sociais a partir de um corpo biológico e sexuado. 
Desse modo, nos inquieta às diversas posições e significados que as práticas corporais, incluindo em partes a GPT, assumem na sociedade, com posicionamentos categóricos binários e que definem quais os movimentos masculinos e femininos. Diante disso, questionamos: a GPT, como conteúdo/objeto de conhecimento da Educação Física Escolar, possibilita a inclusão de todas as pessoas, especificamente quando observado as relações entre corpos e gênero? Assim, o objetivo desse ensaio teórico é refletir e analisar as práticas de inclusão que permeiam a Ginástica para Todos (GPT) na Educação Física Escolar, atentando-se às relações sociais de corpo e gênero.

O presente trabalho se caracteriza como uma ensaio teórico, entendido, conforme Meneghetti (2011), como uma propositiva inacabada, que possibilita uma reflexão crítica sobre alguma temática e que instiga a uma própria interpretação e conclusão por parte dos/as leitores. De acordo com o autor (2011), "O ensaio é um meio de análise e elucubrações em relação ao objeto, independentemente de sua natureza ou característica" (p. 323). Desse modo, foi utilizado uma documentação indireta, especificamente a partir de escritos primários, para o levantamento de informações e consolidação de um background para a materialização desse material (Marconi, \& Lakatos, 2010). Foram analisados obras que tangem a discussão sobre GPT, práticas inclusivas, corpo, gênero e Educação Física Escolar, de modo a realizar uma aproximação e integração teórica, sobretudo observado que há poucos estudos que tratam explicitamente sobre as relações entre esses objetos.

\section{Prática Pedagógica da Ginástica para Todos (GPT)}

A Educação Física é uma prática pedagógica que no âmbito escolar tematiza um conjunto de práticas corporais, como jogos, esporte, dança, lutas, ginástica, entre outras, que configura uma área de conhecimento chamada de cultura corporal. Pode-se dizer que esses temas da cultura corporal expressam sentidos e significados que interpenetram dialeticamente a intencionalidade e as intenções da sociedade. Deste modo, a análise desses temas leva à leitura da realidade social e ao estabelecimento de práticas pedagógicas concretas vinculadas a um projeto político pedagógico que visa a mudança social (Coletivo de Autores, 2012).

Para Ayoub (1998) e Souza (1997), o termo ginástica vem do grego "gymnastikê" e significa a "Arte ou ato de exercitar o corpo para fortificá-lo e dar-lhe agilidade. O conjunto de exercícios corporais sistematizados, para este fim, realizados no solo ou com auxilio de aparelhos e aplicados com objetivos educativos, competitivos, terapêuticos, etc." (Souza, 1997, p. 24, grifo da autora). Lorenzini (2018) complementa que a ginástica também é reconhecida como "arte de exercitar o corpo nu, inspirada pelo ideal grego de harmonia entre corpo e espírito” (p. 2, grifo da autora). Ou seja, há diversas propositivas conceituais para definir ginástica, mas que ainda carregam uma limitação em como definir essa prática.

Há várias formas de categorizar a ginástica, há uma divisão reducionista que apontam apenas duas categorias, sendo a ginástica competitiva e não competitiva. Porém, optamos em reconhecer e mencionar os cinco campos de atuação proposto por Souza (1997), levando em consideração as intencionalidades e possibilidades de utilização de cada ginástica, sendo: (1) Ginástica de Condicionamento Físico, que visa a melhoria e/ou manutenção das habilidades físicas; (2) Ginástica de Competição, que possui uma normativa rígida e com classificação dos/as atletas; (3) Ginástica Fisioterápicas, que objetiva a prevenção e manutenção de algumas doenças; (4) Ginástica de Conscientização Corporal, para melhora da consciência corporal e postural; e (5) Ginástica de Demonstração, que possui a característica de não competitividade, mas de interação social.

Diante dessa organicidade, concebemos que a ginástica é uma prática plural, carregada de símbolos que são representativos do passado e do presente. A prática da ginástica por tempos foi uma atividade da elite dominante, em sua maioria, para homens. Inicialmente era praticada em instituições militares e as mulheres, por exemplo, eram proibidas de frequentar essas aulas. A posteriori, se tornou uma atividade, também, para as mulheres, mas com particularidades distintivas, compreendendo as faculdades anatômicas, biológicas e 
fisiológicas, além da feminilidade e maternidade (Pereira Filho, 2005). A ginástica se desenvolveu juntamente com as noções de corpo, adaptando às mudanças sociais e políticas. Consequentemente, adequou suas exigências, conteúdos, metodologias e técnicas visando melhorar e atender as necessidades humanas em todas as dimensões: física, psicológica, material, espiritual, econômica, social e outras (Oliveira, \& Nunomura, 2012).

No Brasil, o método francês, desde abril de 1921, substituiu o método alemão de ginástica e passou a ser obrigatório e reconhecido como conteúdo curricular básico a ser desenvolvido nas escolas. Em 1929 passou a ser presente em níveis de ensino das escolas brasileiras, continuando a ser regido por militares que acreditavam que somente eles dominavam o assunto (Pereira Filho, 2005). Com o tempo essa realidade mudou, sobretudo diante das múltiplas formas de desenvolver os conteúdos da ginástica, ampliando a oportunidade de prática para todas as pessoas e encorajando-as a buscar os seus espaços dentro desse universo. Entretanto, ainda fica claro que a prática de exclusão ultrapassa o universo restrito da ginástica, de fato, essa prática está presente nas escolas, nas famílias e nas sociedades que ainda classificam as pessoas por seus corpos e/ou gêneros a partir de uma noção idealizada de sujeito.

Ressaltamos que a ginástica é, considerada atualmente como, conteúdo curricular de acordo com a Base Nacional Comum Curricular (BNCC), atentando que a mesma é organizada e sistematizada de acordo com cada momento da educação, respeitando as faixas etárias e nível de desenvolvimento dos/as escolares. A BNCC elenca as modalidades de ginástica a serem desenvolvidas na escola, sendo que a Ginástica Geral, ou melhor, a Ginástica para Todos, está nesse rol de conteúdos/objetos de conhecimento que compõem a Educação Física Escolar (Brasil, 2018).

A GPT, considerada como uma ginástica de demonstração, é uma manifestação expressiva do corpo em combinação com movimentos acrobáticos, artísticos e musicais. Esse conteúdo/objeto de conhecimento, portanto, deve, também, ser dialogado com outras temáticas de modo a possibilitar a transversalidade do conhecimento, ampliando o olhar sobre a prática e como se relaciona com a realidade. Em suma, consideramos a GPT uma prática capaz de fomentar a prática inclusiva no que tange aos diferentes corpos e gêneros.

De acordo com a Federação Internacional de Ginástica (FIG), a GPT tem como princípio fundamental a busca do lazer, onde pessoas de todas as idades, gêneros, etnicidades, classes sociais etc., participam pelo prazer de sua prática, para desenvolver a saúde, o condicionamento físico, a interação e integração, contribuindo para o bem-estar físico, social e psicológico, respeitando as tradições, interesses e características de cada povo (Souza, 1997). Concomitantemente, a Confederação Brasileira de Ginástica (CBG) apresenta na GPT as possibilidades de valorização do intercâmbio sociocultural, de autossuperação, de respeito coletivo e individual, além de dar oportunidade a um número maior de indivíduos poderem praticar atividades físicas baseadas na ginástica. Mantendo a essência e elementos próprios da ginástica, as composições coreográficas possibilitam vínculos de inclusão, sociabilidade, afetividade, além de contato com outras áreas artísticas como a dança, as artes circenses, as artes cênicas e outras várias áreas expressivas, resultando assim em produções corporais espontâneas e alegres que contextualizam as mais diversas temáticas culturais e sociais (Fernandes, \& Ehrenberg, 2012).

Leles et al. (2016, p. 40) apontam a GPT da seguinte forma:

A Ginástica para Todos possui características [...] acessível a todas as pessoas, aberta para a participação; como uma ginástica de grupo, com grupo; como uma ginástica simples, sem restrições e regras e que, portanto, cria espaço para a diversidade e para a criatividade; e, em especial, como uma ginástica do prazer, da felicidade e do divertimento. Nessa modalidade o respeito à individualidade e particularidades de cada sujeito envolvido se encontram sempre presentes, possibilitando a participação irrestrita de pessoas, em qualquer idade, sem habilidades gímnicas prévias, sem discriminação de gênero e/ou delineamento de estereótipos físico/anatômicos.

O corpo assume um instrumento de extrema importância na GPT, representando uma diversidade de movimentos, linguagens e expressões. Parte do pressuposto que esse corpo está em constante construção e que 
a própria GPT se reconfigura a partir das ações provindas da pluralidade cultural e territorial, por exemplo. $\mathrm{O}$ reconhecimento da numerosidade de manifestações e movimentos corporais da e na GPT busca, através de ideias, diálogos e ações, ir de encontro contra os discursos hegemônicos e excludentes presentes na ginástica competitiva, como a supressão dos menos habilidosos e a normatização do uso de aparelhos para algumas categorias (Fátima, \& Ugaya, 2016). Isto é, percebe-se que a GPT intenta o rompimento com as estruturas e instituições normatizadoras que definem e estereotipa algumas modalidades de ginástica, onde os mais "habilidosos, fortes, viris e saudáveis" são rotulados como os "perfeitos" para essa prática corporal.

Partindo dos pressupostos de pluralidade e participação, Fátima e Ugaya (2016) discorrem que algumas práticas e processos pedagógicos fortalecem ideários estereotipados e preconceituosos que, segundo as autoras (2016), predominam na cultura. Essa problemática é visível em movimentos de força, garra, destreza e poder para os meninos e para as meninas movimentos de leveza, graciosidade, beleza e ternura. As múltiplas formas de explorar as práticas de GPT contribuem para superar esses estigmas que demarcam os movimentos corporais e as funções e papéis de gênero na ginástica, possibilitando reflexões sobre essas ações.

Ao utilizar tanto aparelhos oficiais quanto os não oficiais, em ambientes formais, informais ou educacionais, e por não ter normativas rígidas e restritivas, a GPT proporciona uma vasta possibilidade de experimentação sem restrições. Na prática, homens podem utilizar materiais e realizar movimentos que são característicos da Ginástica Artística Feminina, ou materiais da Ginástica Rítmica, como fitas, bolas, arcos etc., e, por outro lado, as mulheres, da mesma forma, podem realizar exercícios em aparelhos e movimentos que são considerados masculinos. Vale lembrar que por mais que os elementos técnicos não sejam o objetivo principal da GPT, ela desenvolve uma base motora para que os/as escolares possam realizar os movimentos com eficiência e eficácia simbólica. Além desse desenvolvimento motor, as relações afetivas e sociais também são fomentadas pela prática da GPT (Leles et al., 2016).

As pluralidades presentes na GPT, por meio da cultura, concretizam corpos encarnados e incorporados no mundo (Fátima, \& Ugaya, 2016). As diferenças existentes dessa ginástica com as demais são concebidas pela importância atribuída a todas as pessoas envolvidas, desde as práticas pedagógicas até o momento de criação coreográficas, além de ressaltar os elementos de cooperação, liberdade, prazer pela prática, a inclusão, entre outros (Carvalho, 1998). As atividades da GPT possuem uma riqueza de elementos que engrandece e potencializa essa modalidade (Souza, 1997), proporcionando diferentes formas de trabalho, com variedades de tradições, símbolos e tendências que contribuem nos valores culturais de cada povo.

Como dito anteriormente, é importante entender a GPT como uma forma de expressão que possui liberdade gestual, corporal e criativa sem perder a essência de modalidade gímnica, transcendendo uma simples prática corporal e de composição coreográfica que pode ser apresentada em festivais. Ela deve ser entendida na totalidade e trabalhada como tal, constituindo um processo contínuo de formação e transformação dos/as praticantes, sejam eles/as escolares ou professores/as. E é a partir desses conceitos que entendemos que todas as pessoas envolvidas têm uma grande significância para as aulas e para o processo de construção.

Oliveira e Lourdes (2004) discorrem que a GPT é umas das práticas exequíveis no contexto educacional e de entretenimento, tendo o papel de desconstruir a ideia reducionista ligada à ginástica como uma prática competitiva, privilegiando a demonstração/apresentação, além das manifestações de movimentos. "Sua riqueza está exatamente no princípio de privilegiar todas as formas de trabalho, estilos, tendências, influenciados por uma variedade de tradições, simbolismos e valores que cada cultura agrega" (Oliveira, \& Lourdes, 2004, p. 226). Há uma abundância plástica e artística dos corpos através da expressão do movimento, ao passo de que os/as praticantes e/ou escolares tenham novas possibilidades de exploração das "linguagens culturais" que contam, jogam e dançam o folclore e outros temas territoriais e, assim, permite uma ampliação das experiências e dos conhecimentos acerca da diversidade cultural, incentivando a prática desse conteúdo no âmbito escolar. 
Vislumbramos a GPT na escola como uma prática que não está associada a corpos ou gêneros em específico, pois a contextualização e problematização de determinadas situações reais da sociedade devem estar presente nas aulas, havendo uma aproximação teórico-prática dessas com os conteúdos/objetos de conhecimento e movimentos da GPT. Os momentos das aulas devem ser alicerçados em uma perspectiva de que os sujeitos possuem a mesma importância e de que as práticas da modalidade se constituem por essa pluralidade e pela coletividade. Assim sendo, a GPT deve ser compreendida como uma possibilidade de vivência das diversas modalidades gímnicas, sem restrição e categorização do que é para homens e para mulheres, e que visa o ensino da técnica sem engessar os movimentos, fazendo uso da liberdade de criação para dialogar com diversos temas do cotidiano e da cultura corporal de movimento, dando ênfase na ludicidade, na sociabilidade e na reciprocidade entre os/as praticantes.

Leles et al. (2016) apontam que a GPT tem-se mostrado eficaz em garantir a identidade da ginástica, mantendo seu conteúdo e forma, rompendo com os aspectos meramente técnicos e competitivos. A compreensão de que a ginástica também é expressão acaba ampliando as formas como as atividades e exercícios gímnicos são trabalhados durante as aulas de Educação Física Escolar, possibilitando comunicações internas e externas, seja na forma em que os sujeitos percebem o próprio corpo, suas identidades e qualidades, seja no contato com outras pessoas de cultura e meios sociais diferentes ou não.

É esperado um certo padrão corporal em cada modalidade da ginástica (Gomes et al., 2020). É comum depararmos com um estereótipo corporal, um biotipo, que é relacionado às práticas de ginástica e suas variações. Contudo, isso não será um delimitante na prática da GPT, sobretudo no contexto escolar.

Um dos grandes diferenciais adotado pela GPT, em sua essência, é que não há a exigência de um biotipo e/ou gênero específico. É apreciado o interesse e/ou a vontade das pessoas em participar, o que já torna o corpo do/a praticante "propício" para essa modalidade. Além disso, Gomes et al. (2020) apontam a democracia fundamental presente na GPT que considera como elementar as observações sobre os contextos sociais, históricos de vida, realidades locais e conjunturas globais dos corpos que praticam a modalidade, resultando não apenas na inclusão de habilidades e experiências pessoais e coletivas, mas em um processo de ressignificação daquele grupo de praticante.

As problemáticas estruturais do ambiente escolar apresentadas pelo Coletivo de Autores (2012) são fatores que acabam por desestimular os/as professores/as ao ensino de ginástica, podendo ser justificado pela ideia vinculada à esportivização da modalidade, o seu padrão estereotipado de técnicas e a seletividade de gênero existente nas provas (aparelhos).

Aprender Ginástica Geral na escola significa, portanto, estudar, conhecer, compreender, confrontar, vivenciar, apreender as inúmeras interpretaçôes da Ginástica para, com base nesse conhecimento, buscar novos sentidos e significados e criar novas possibilidades de expressão gímnica. (Ayoub, 1998, p. 127).

Assim, compreendemos a GPT como uma prática que possui comunicações, linguagens e expressões que contêm e apresenta inúmeras possibilidades de movimentos e reflexões aos praticantes, em especial aos/às escolares, proporcionando bem-estar e ressignificando as expressões corporais que são culturalmente vividas na realidade social dos/as praticantes.

\section{Da Prática de Exclusão à Constituição da Inclusão na Educação Física Escolar}

Propomos uma reflexão sobre a prática de exclusão e inclusão, com o propósito de nortear, adequadamente, nossa perspectiva de diálogo. As inúmeras práticas de segregação e exclusão salientam a ótica acerca dos menos favorecidos. Lima (2014) discorre que a "discriminação e exclusão levou a pensar nos grupos que são marginalizados, subordinados e considerados inferiores” (p. 40). Evidenciamos que as desigualdades encontradas no convívio social são como pontos iniciais para essas condutas, o que aumenta a rejeição e neutraliza o sujeito e sua representação perante a sociedade que o torna inferiorizado. $\mathrm{O}$ 
impedimento/limitação, situação percebida em alguns setores da sociedade, reflete a exclusão de determinados grupos sociais quanto ao acesso à educação, trabalho e saúde, por exemplo. $\mathrm{O}$ uso de termos com cunho pejorativo torna-se produto de rotulagem, cheios de preceitos e estigmas, que despertam preconceitos e, assim, trazem limitações ao pensamento acerca desses sujeitos.

A sociedade brasileira é culturalmente eivada de preconceitos. Assim, ressalta-se a importância de calcar as ações em princípios de lutas que apontem para a conscientização dos sujeitos, tendo em vista desenvolver novas relações sociais em busca da transformação do ser humano. Excluir e discriminar pessoas ou grupos ainda é uma prática muito presente e se não fossem os movimentos sociais, pelas pressões que deram origem às normas punitivas contra tais ações, não haveria, hoje, diversos regulamentos visando incluir as pessoas [...]. (Lima, 2014, p. 42)

Diante do contexto social de discriminação dos grupos minoritários, a segregação e a exclusão evidencia a justificativa da existência da variabilidade de legislações inclusivas, como tentativa de equacionar as problemáticas societárias, apontando aos reflexos da exclusão nos diversos espaços sociais. Os dilemas e bloqueios societários são ocultados, consecutivamente, a exclusão se encontra como um "amuleto" das pessoas que evitam a aproximação e/ou oportunidades para alguns grupos de pessoas. Isso impossibilita novas relações sociais, fundando uma cultura de preconceitos, impossibilitando conviver e aprender com a diversidade (Silva et al., 2008).

Nesse ínterim também refletimos e discutimos que a prática de inclusão não deveria ser pensado somente como uma abordagem para determinados grupos de pessoas, como, por exemplo, as pessoas gênero divergentes, mas para todas as pessoas e/ou comunidades. Embora a prática de exclusão refere-se àqueles que são considerados como marginalizados, menos habilidosos, por características de sexo e gênero, grupos tradicionais e outros, devemos ponderar a inclusão em uma perspectiva macrossocial, ou seja, deve-se pensar nas demandas sociais com a finalidade de promover políticas públicas de acesso a todos os serviços da sociedade, em especial aos espaços educacionais e para os exercícios físicos e esportivos.

Para Silva et al. (2008) os princípios de normalização, integração e inclusão foram os caminhos percorridos para se chegar à inclusão. Os autores (2008) perceberam algumas transformações históricas e culturais provindas da necessidade de superação de uma organicidade tradicional da sociedade, almejando diminuir as desigualdades, valorizando a ideia de que todos são iguais e possuem direitos sociais. A diversidade passa a ser considerada como um dos princípio da inclusão, visto considerar que todos são diferentes e singulares.

Pensar a inclusão, portanto, é diminuir todas as formas e práticas de exclusão que estão presentes nas raízes da sociedade. É desconstruir e ressignificar todo sistema de pensamento que possa deturpar o ser humano na sua essência, desnaturalizando atitudes, concepções e decisões excludentes que estiveram e estão presentes na sociedade, visando uma transformação social na direção de uma humanidade com maior equidade e igualdade perante às diferenças.

Precisamos enfrentar os desafios, mas não podemos "abraçar" a inclusão sem considerar as ideias liberais contidas nos discursos, as restrições, os pontos fundamentais e determinantes levantados nos estudos e pesquisas, tanto em nível nacional quanto internacional, as especificidades de cada deficiência e do alunado da Educação Especial. Também não podemos deixar de pensar em como articular o tempo, o espaço e o conhecimento na Educação Física Escolar que contemple não só o aluno com deficiência, mas o princípio da diversidade (singularidade) e da diferença na unidade (universalidade). (Silva et al., 2008, p. 132)

Cada indivíduo é dotado de elementos que ressaltam sua subjetividade. A ideia de "corpo ideal” pode se desfazer e ganhar nova roupagem ao perceber o corpo com singularidades próprias, pois, aquilo que torna diferente é o que faz o corpo singular, próprio, desconstruindo os rótulos instituídos pelo meio social. Dessa maneira, as práticas de inclusão podem se tornar mais complexas devido às inúmeras possibilidade de pensar nas unicidades do(s) corpo(s), considerando as demandas e necessidade individuais. As intervençóes seriam mais eficazes ao entender essas demandas e particularidades do sujeito e do coletivo. Tal como ocorre com o corpo, as questões de gênero precisam ser problematizadas e discutidas, uma vez que a perspectiva hegemônica masculina é sobressaltada. 
Assim, cada indivíduo é dotado de elementos que ressaltam sua subjetividade, e ao perceber o seu corpo com singularidades próprias, a ideia de "corpo ideal" pode se desfazer e ganhar nova roupagem, pois, aquilo que torna diferente é o que faz o corpo, desconstruindo o rótulo instituído pelo meio social. A possibilidade de pensar na singularidade do corpo contribui para que as práticas de inclusão se tornem mais complexas, visto que as demandas e necessidade são individuais. Porém, as intervenções seriam mais eficazes ao entender essas demandas e particularidades do sujeito e do coletivo. Tal situação também ocorre com as questões de gênero. Louro (2013) destaca o próprio discurso da masculinidade, "branco ocidental, heterossexual e de classe média" (p. 44), se tornando categoria de desejo, alcance, vontade por todos/as, o que denominamos como: padrão social a ser buscado e que está sendo reforçado não somente pelas instituições sociais, mas nos livros literários, didáticos, nas propagandas, nas revistas, nas embalagens de produtos, entre outros.

As práticas inclusivas caminham por espaços não existentes anteriormente, ganhando destaque. Todavia, as dificuldades estão sempre presentes, de formas explícitas ou veladas. Atualmente o ser humano desvela sua historicidade corporal, de gênero e identitária através de uma transformação gradativa, e essa transformação possibilita oportunidades e, talvez, equidade. Silva et al. (2008) apontam "que na educação física inclusiva precisamos de uma prática sócio-político-pedagógica capaz de materializar-se em uma nova Educação Física Escolar e novos caminhos a serem percorridos" (p. 133).

É evidente que, em alguns contextos, as aulas de Educação Física ainda possuem características de verdadeiros treinamentos esportivos com a finalidade de obter os melhores resultados nas competiçóes e que definem quais são os estereótipos de corpo e gênero. Mesmo com as transformações epistemológicas da área e propostas metodologias específicas para cada âmbito, ainda há uma aproximação dos procedimentos e métodos no sentido de melhorar as habilidades físicas, técnicas e táticas, enfatizando as questões biológicas. González e Fensterseifer (2010) destacam algumas áreas científicas que respaldam essa perspectiva de preocupação e cuidado com o corpo e/ou saúde, sendo a "saúde coletiva, epidemiologia, fisiologia, anatomia” (p. 16), entre outras. Percebemos que é comum que escolares obesos/as, tímidos/as, desajeitados/ as, com deficiência e/ou simplesmente menos habilidosos/as passem a constituir a categoria de excluídos no contexto escolar, simplesmente por não se "encaixarem" nos padrões preestabelecidos pela sociedade e, também, por algumas abordagens da disciplina.

No entanto, o papel da Educação Física é de encaminhar e orientar os/as escolares a uma relação lúcida com o meio social, consigo e com o outro, assumindo-se como uma disciplina curricular com responsabilidade específica, visando a formação integral dos/as escolares. A Educação Física Escolar tem “a possibilidade de colocar em questão os sentidos hegemônicos que nelas predominam e que se apresentam como que 'esquecidos' da sua condição de uma possibilidade de sentido" (González, \& Fensterseifer, 2010, p. 18), ou seja, é possível problematizar e contextualizar os conteúdos/objetos de conhecimento da Educação Física a partir de diferentes metodologias que objetivam uma nova óptica sobre todo o sistema, compreendo a pluralidade de manifestações corporais, identitárias e de gênero.

Também não deixamos de frisar que as questões de gênero são refletidas nesses espaços escolares, onde por vezes ocorrem a aplicação de atividades que visam um grupo específico, como é o caso do conhecido "rola bola", cuja ação do/a professor/a é de distribuir materiais didáticos ao grupo (Machado et al., 2010), atendendo aos interesses hegemônicos e esportivizados de determinados guetos culturais, reforçando o "caráter constitutivo, produtivo e regulador da cultura escolar" (Spolaor, \& Nunes, 2020, p. 634). Isso acontece não somente em detrimento da didática aplicada pelo/a professor/a, mas pela forma em que os próprios escolares contribuem, impedindo a participação de alguns, já que o objetivo a cada "aula/treino" é sempre o de vitória (Borella, \& Denari, 2013).

Taffarel (2016), ao discutir sobre as metodologias de ensino da Educação Física, apresenta que para a compreensão da realidade histórica dos seres humanos novos sentidos e significados vão sendo constituídos a partir dos avanços inerentes às práticas corporais. Logo, há um desenvolvimento de técnicas e tecnologias que exprimem uma busca por uma plasticidade dos exercícios corporais, nesse caso, os exercícios gímnicos e em 
seus fundamentos básicos (andar, correr, saltar, rolar, girar, arremessar, equilibrar, rastejar, balança e trepar). Explicitamos que a Educação Física, ora reproduz práticas inclusivas, dando possibilidades e oportunidades aos sujeitos, ora apresenta práticas de exclusão servindo como reforço à discriminação, ou seja, os dois processos ocorrem concomitantemente na sociedade e, nesse caso, na escola.

O conteúdo da ginástica, em particular a GPT, possui uma perspectiva metodológica da não exclusão, acentuando que todas as pessoas têm o direito de participar e se movimentar. As propostas dessa modalidade são ilimitadas, havendo preocupação com as práticas inclusivas e de interação daqueles que ali estão, independentemente de suas diferenças de corpo e gênero. Revelando esse cuidado em sua aplicabilidade, Toledo e Silva (2020) destacam que a maior riqueza da GPT é seu caráter mutável e adaptável afirmando que

Podemos dizer que isso é um dos seus trunfos, pois sua plasticidade permite a inclusão de diferentes faixas etárias, tipos de corpos, gêneros em espaços sociais diversos e apresenta soluções para a prática corporal vencendo desafios, seja o de realizar uma parada de mãos com o auxílio de um colega de grupo até o de expressar-se em público, dentre tantas outras situações que assistimos, seja em suas aulas ou em suas apresentações (Toledo, \& Silva, 2020, p. 78).

Os/as professores/as que utilizam desse conteúdo/objeto de conhecimento consideram que as diferenças e particularidades dos sujeitos não devem ser limites e/ou restrições, mas, sim, possibilidades, permitindo uma aplicabilidade desse conteúdo nas aulas e uma maior aceitação por partes dos/as escolares. Isso é viável devido a multiplicidades de possibilidades pedagógicas que consideram os/as escolares e seus movimentos como únicos, respeitando as diversidades, os corpos e as características individuais e coletivas (Maroun, 2015).

\section{InTERSECCIONALIDADE CoRPo E GÊNERo NA GPT}

Reforçando a concepção de gênero, fica claro a referência a um dispositivo que une o meio político, cultural, social e histórico, com pré-discursos que estabelecem quais são os comportamentos, pensamentos e sentimentos de cada pessoa de acordo com algumas características. Consideramos como um instrumento e uma ferramenta teórica visto na prática que fortalece o processo da construção social. Estamos acostumados/ as com ideais binários fixos referentes ao que é para cada gênero, mas é valioso reforçar que gênero está longe de ser efeito de um sistema fechado de controle e poder, ainda que seja um definidor de quem detêm esse poder. Essa construção é representada e dialogada pela sociedade, nas escolas, nas instituições familiares, na mídia, igreja e até mesmo em algumas áreas do conhecimento, como na medicina (Preciado, 2011).

Para além de representações e ferramentas, também podemos compreender o corpo, assim como o gênero, como potência política, e que através de suas ações exercem diversas funções e papéis postos ou não a ele, de maneira não fixa, sendo uma verdadeira constância ondulatória. Na aproximação com o corpo, o gênero pode ser uma circulação de influências contínua. Preciado (2011), em uma de suas colocações, aponta que "É nessa circulação diferencial de fluxos [...] que se desempenha a normalização contemporânea do corpo.” (p. 13).

O corpo a todo o momento está sendo construído e produzido de diversas formas, seja na escola, no ambiente familiar e nos ambientes públicos de lazer, influenciado e moldado diariamente de forma direta ou não, através dos gestos, símbolos, normas e regras que estão inseridos dentro das práticas corporais. A ginástica, particularmente a GPT, tem se tornado uma prática mais inclusiva e menos naturalizada (Felipe, 2013) diante de corpos considerados perfeitos e capazes de realizar acrobacias, passando se vista como uma atividade que intui o ingresso e permanência de pessoas com corpos, identidades e gêneros distintos.

O corpo é uma representação da pessoa, seja pelas marcas, gestos, linguagens ou pelos acessórios utilizados no dia a dia, tal constituição se dá mediante as interações com o outro e consigo, em ambientes privadas e/ ou públicas. $\mathrm{O}$ corpo não é máquina, não é estático, mas as vezes se mostra mecanizado. Esse corpo produz sentidos e significados, onde desde o nascimento esse processo é contínuo e por meio de como as relações com outros vão se construindo, reinventando e moldando suas formas (Le Breton, 2007). Apesar de parecer autorepresentativa, essa imagem pode ser reducionista, pois o corpo não é somente uma evidência de uma 
estrutura simbólica proveniente de elaborações sociais e culturais. O corpo, é o primeiro e o mais natural instrumento do ser humano e, que conforme os hábitos culturais, produz eficácias práticas.

Em concordância com Gomes et al. (2020), o corpo e suas manifestações se relacionam com a natureza através de suas atividades, como é no caso da prática da GPT. Essa situação se dá pelo reconhecimento dessa modalidade, predominantemente, demonstrativa e que abre espaço para a contribuição, realização e apresentação acerca de uma melhor forma de se fazer e praticar ginástica, além de permitir e buscar a participação de todos/as, através da formação de grupos mistos e diversificados, sem distinção de gênero, idade e habilidades, podendo assim desenvolver diversos potenciais de cada participante dentro de suas próprias limitações (Gomes et al., 2020).

Partindo por entre limitações, o corpo, esse objeto tão discutido e enfatizado nesse ensaio teórico, ocupa diferentes posiçóes de acordo com espaços e contextos em que se encontra, corpo já classificado como centro, referência, mas também como estranho, raro e excêntrico, como citado por Louro (2013). Partindo desses opostos, é de grande valia refletir sobre as influências que o corpo recebe diante de práticas expressivas e de relações que vão sendo construídas no meio e com o outro. Para isso, é necessário resgatar para o diálogo a ideia de corpo estereotipado e universal que seria aquele reforçado por ideias hegemônicas, como o patriarcalismo, influenciado pela ciência positivista e que reflete noçóes de centro e supera todas as expectativas e perspectivas que são criadas a partir e para ele. Pensando esse corpo idealizado e padronizado que reforçamos reiteradamente e em consonância com as reflexões feitas por Louro (2013), de que não é somente as pessoas que estão dentro dos padrões estabelecidos que reforçam os discursos excludentes e hierarquizados, mas também pelas próprias pessoas que são categorizadas como subalternizadas.

O que nos interessa é resgatar essa complacência que a GPT tem em sua essência humanista, que diante das práticas e dos movimentos desconstrói discursos hegemônicos e segregacionistas, ressaltando e respeitando a diversidade. Reforça ainda mais a perspectiva de corpos e gêneros plurais, abandonando todas as construções que estão relacionadas ao binarismo e a ideia de centro, buscando pela diferença a transformação de determinados pensamentos e ideais. É preciso pensar para além dos dispositivos de controle social que definem as características corporais e as funções e papéis sociais e de gênero das pessoas, intencionando o rompimento de pensamentos preconceituosos e excludentes. Essas reflexóes nos fazem pensar ainda mais sobre os corpos e as questões de gênero e todas as analogias difíceis de romper devido a um dualismo fortemente idealizado.

Ao tratar da minoria, marcada pelos atributos do que é diferente, abjeto e indesejável, percebemos que tudo que não está dentro dos dispositivos de controle social dos grupos conservadores é considerado anormais ou abjeto. Toda criação humana é uma construção e essas fronteiras, seja na discussão de identidade, preconceito ou tarefa, gera práticas e políticas de exclusão e inclusão. Scott (2005) chama esse paralelo de paradoxal, isto é, há uma ampliação de discussões a respeito dos dispositivos que compõe o controle social e que não pode ser resolvido, pois, é falso e verdadeiro ao mesmo tempo.

As normas são regulatórias, seja na dança, no esporte, na luta, nos jogos e na ginástica. Elas são capazes de direcionar aquilo que é nomeado. Na GPT há esse desvio da norma uma vez que desconstrói algumas formas e movimentos característicos de outras ginásticas, entendendo que todos os corpos e gêneros conseguem performar e praticar a modalidade. Essa situação difere de outras ginásticas, como a Ginástica Artística e a Ginástica Rítmica, as quais possuem um aparato que sustenta os ideias de como os corpos devem se movimentar e em quais categorias os gêneros se enquadram. Algumas práticas de ginástica ainda são caracterizadas pela maioria das pessoas como mais adequada para as meninas/mulheres devido a sua performatividade e pela manifestação de ritmos, cores e belezas. Entretanto, é importante e necessário reconhecer as inúmeras formas de expressão, na tentativa de reforçar identidades pluralizadas, não substanciando a ideia do que é de menino/menina. Infelizmente, e observando a historicidade, a ginástica tem um marco em potencializar a feminilidade carregando influências culturais e sociais. Essa situação tem 
sido invalidada diante das novas transformações das modalidades e das possibilidades de práticas, sobretudo com as perspectivas de práticas inclusivas através da GPT.

Presentemente, como citado, a ginástica está estigmatizada como uma prática feminina, possivelmente, por sua exigência de plasticidade. Algumas práticas gímnicas como a ginásticas de academia e as ginásticas competitivas estão delimitadas a certos corpos e gêneros, consequência de uma sociedade normativa que remaneja e adota diversos critérios de seleção para a atuação corporal, interseccionalizando, também, com as questões de gênero. Ao tratar a GPT, reforçamos a ideia já mencionada anteriormente de que não há restrição de participação quanto aos corpos e gêneros, o que corrobora com a perspectiva de que todas as pessoas possam participar, nesse casos todos/as escolares. A prática de GPT tem um caráter expressivo e que visa representar algo, inúmeras vezes contextualizando e problematizando situações que ocorrem no cotidiano, o que de fato contribui para uma ressignificação e transformação da sociedade.

Ainda fazendo alusão à GPT, é importante argumentar que a igualdade e a diferença não são similares e tão pouco opostas, mas é através das diferenças que é possível chegar ao reconhecimento da igualdade em níveis de excelência, posição, dignidade, habilidade, realização e poder (Scott, 2005). Sobre essa discussão é importante começar e recomeça-la, pois o binarismo, quando não questionado ou descrito, é uma armadilha para a hierarquização, separação e dominação. A GPT nos convida a pensar para além do corpo, das ideias de homem e mulher, masculino e feminino, mas a (re)pensar as diferenças em questão. Louro (2013) complementa que "ao ocupar, excepcionalmente, o lugar central, a identidade 'marcada' continua representada como diferente” (p.47) e é nessa perspectiva que estudos sobre representatividade alinhada a historicidade do corpo e gênero se tornam importantes, tencionando para além das questões físicas e sociais do momento.

Mesmo com todas as desconstruções culturais e a busca incansável pela inclusão, na qual a GPT se enquadra, ainda é perceptível a produção de corpos e gêneros, indireta e diretamente, num padrão estético idealizado e cultuado pela indústria cultural. Embora a GPT não construa uma ideia de corpo "perfeito" e de gênero, as pessoas ainda estão imersas numa cultura norteada por concepções e perspectivas que atribuem certas características físicas e estéticas, além de funções e papéis de gênero às pessoas. Toda essa base cultural está naturalizada, enraizada, nas pessoas, crianças, adultos e idosos, homens e mulheres, e outros.

Para findar esse momento, faz-se necessário refletir o contexto das relações de corpo e gênero com a GPT, com destaque para o papel social da Educação Física no processo de desenvolvimento dos/as escolares nos ambientes de atuação profissional. Refletir sobre as análises a respeito da construção e das influências constantes que o corpo recebe e produz sobre as relações de gênero pode ajudar a diminuir as desigualdades postas e instituídas nas práticas corporais, sobretudo, na Educação Física Escolar. Assim, a GPT pode colaborar com a construção de uma sociedade plural, igualitária e equitativa e, além disso, a GPT pode ser responsável em transformar a realidade vigente na medida em que suas atividades podem amparar a des-resconstruir as perspectivas hegemônicas de corpo e gênero na sociedade.

\section{Considerações Finais}

Os diversos apontamentos presentes nesse ensaio teórico apresentam a (re)formulação de uma tese que esclarece pontos imprescindíveis para a práxis pedagógica da Educação Física no que se refere ao trabalho com a GPT. Neste sentido, esse estudo levanta ideias que ajudam a compreender a profundidade das relações sociais e apresenta perspectivas para uma transformação social e, assim, ruma na busca de um rompimento com paradigmas discriminatórios e em direção aos pensamentos emancipatórios.

Diante das características que definem a GPT, como a flexibilização de regras preestabelecidas e a ausência de competições, descentraliza um ideário de exclusão e de esportivização. Com isso, a GPT rompe com padrões corporais idealizados e inalcançáveis, bem como com as normativas presentes em alguns discursos de professores/as e praticantes de modalidades competitivas. Embora ainda haja desigualdades nas práticas das ginásticas, como em qualquer setor da sociedade em geral, intui-se que a GPT seja uma prática enriquecedora 
para a Educação Física Escolar, uma vez que ela pode contribuir com o desenvolvimento plural dos/ as escolares, com a ruptura de estereótipos técnicos e corporais e, sobretudo, por borrar as definições universalizantes de corpos e gêneros.

Quanto às práticas pedagógicas com a GPT, ainda é possível perceber algumas concepções generalizadas que enfatizam, sobretudo, dificuldades de aplicar essa modalidade em alguns ambientes. Além disso, há a dificuldade de alguns/algumas professores/as abordarem de forma transversal as temáticas de corpo e gênero nas aulas de Educação Física. Essa situação pode estar enraizada na sociedade escolar e nas práticas gímnicas, podendo ser ressignificada a partir da expansão de teorias e abordagens que reflitam a necessidade de pensar a GPT como uma ferramenta que não categoriza e que não exclui segundo marcadores sociais de corpo e gênero. Por sua perspectiva de adoção da pluralidade e criação de possibilidades de movimentos, linguagens, expressões e estéticas corporais, a GPT se apresenta como uma modalidade possível na Educação Física Escolar e que ajuda a discutir os processos de (des)construção de corpos e as desigualdades atribuídas aos sentidos, funções e papéis de gênero.

O respeito às diferenças de corpos e à equidade de gênero, assim como a ruptura com a estereotipação de técnicas e movimentos, devem ser repensada pelos/as professores/as de Educação Física. A sua práxis pedagógica precisa primar pela conscientização da pluralidade de manifestações corporais, de corpos e de gêneros. É nossa responsabilidade, como professores/as de Educação Física, buscar a concretização de processos de formação e desenvolvimento de valores e atitudes que tenham como base o respeito mútuo, a dignidade, a solidariedade, a afetividade e a coletividade dos grupos escolares.

Por fim, se faz importante ampliar e referenciar a diversidade como categoria da GPT que lhe torna tão potente como conteúdo da Educação Física Escolar. Consideramos necessário a construção de práticas reflexivas que promovam uma formação a partir e que compreenda as diferenças humanas, que seja capaz de questioná-las e (re)pensa-las. Deste modo, estamos a partir das vivências com a GPT, encontrando e construindo novas condições para incluir corpos e gênero.

\section{REFERÊNCIAS}

Ayoub, E. (1998). A ginastica geral na sociedade contemporânea: respectivas para a Educação Física escolar. Tese (doutorado) - Universidade Estadual de Campinas, Faculdade de Educação Física, Campinas, SP. Recuperado de: http://www.repositorio.unicamp.br/handle/REPOSIP/274879

Borella, D. R., \& Denari, F.E. (2013). Atividades de ginástica acrobática como contribuição para a inclusão. inclusiva na qualidade de vida de pessoas com deficiência. In: Busto et al. (Ed.). Esporte, reabilitação e educação física inclusiva na qualidade de vida de pessoas com deficiência [livro eletrônico]. Londrina: Eduel.

Brasil. Ministério da Educação (2018). Base Nacional Comum Curricular. Recuperado de http://basenacionalcomu m.mec.gov.br/abase/

Butler, J. (2003). Problemas de gênero: Feminismo e subversão da identidade. Rio de Janeiro: Civilização Brasileira.

Carvalho, R. E. (1998). Temas em educação especial. WVA.

Coletivo de Autores (2012). Metodologia do ensino de educação física. Cortez Editora.

Domingues, L. S., \& Tsukamoto, M. H. C. (2021). Ginástica para todos e lazer: onde seus caminhos se cruzam?. Corpoconsciência, 171-186. Recuperado de https://doi.org/10.51283/rc.v25i1.11921

Fátima, C. V.\& Ugaya, A. S. (2016) Ginástica Para Todos e pluralidade cultural: movimentos para criar novos pensamentos. In: Oliveira, M.; Toledo, E. (org.) Ginástica para Todos: possibilidades de Formação e Intervenção. Anápolis: UEG, 141-154.

Felipe, J. (2013). Erotização dos corpos infantis. Corpo, gênero e sexualidade: um debate contemporâneo na educação. In Goellner S. V. (Eds). Corpo, gênero e sexualidade. 9. ed. Petrópolis, RJ: Vozes. 
Fernandes, M. R. C., \& Ehrenberg, M. C. A (2012). Ginástica para Todos na sua relação com as atividades físicas orientadas para o lazer. EFDeportes, 15(166). Recuperado de https://www.efdeportes.com/efd166/a-ginasticapara-todos-para-o-lazer.htm

Gomes, L. C. N., Iwamoto, T. C., Baptista, T. J. R., \& de Oliveira, M. F. (2020). O corpo a partir da ginástica para todos: primeiros debates com o Grupo Cignus. Corpoconsciência, 24(1), 83-94. Recuperado de http://periodico scientificos.ufmt.br/ojs/index.php/corpoconsciencia/article/view/9764

González, F. J.; Fensterseifer, P. E. (2010) Entre o "não mais" e o "ainda não": pensando saídas do não-lugar da EF escolar II. Cadernos de Formação RBCE, 10-21. Recuperado de http://rbce.cbce.org.br/index.php/cadernos/ar ticle/viewFile/978/561

Lanz, L. (2015). O Corpo da roupa: a pessoa transgênera entre a transgressão e a coformidade com as normas de gênero. Recuperado de https://www.acervodigital.ufpr.br/handle/1884/36800

Le Breton, D. (2007). A sociologia do corpo. Petrópolis, RJ: Vozes.

Leles, M. T., Nakatani, L. Z. C., Souza, S. D., Lopes, L. T., Neto, O. V., \& Monteiro, T. S. (2016). Ginástica para Todos na extensão universitária: o exercício da prática docente. Conexões, Campinas, 14(3), 23-45. Recuperado de htt ps://periodicos.sbu.unicamp.br/ojs/index.php/conexoes/article/view/8648060

Lima, E. T. (2014). Politica de inclusão: um estudo na rede pública de educação em Jataí-Goiás. 2014. $179 f$ (Dissertação de mestrado - Programa de Pós-graduação em Educação, Pontifícia Universidade Católica de Goiás, Goiânia).

Lorenzini, A. R.. (2018) O conteúdo ginástica em aulas de Educação Física escolar. In: Souza Júnior, M. (Org.). Educação Física Escolar: teoria e política curricular, saberes escolares e proposta pedagógica. $3^{\mathrm{a} e d . R e c i f e: ~ E D U P E, ~} 3$. Recuperado de http://www.einsteinlimeira.com.br/painel/uploads/28_02_2012_16_26_54ginasticas_com_ gimnica_o_conteudo_ginastica_em_aulas_de_ef_escolar.pdf

Louro, G. L. (2013). Currículo, gênero e sexualidade. In: Louro, G. L.; Felipe, J.; Goellner, S. V. (org). Corpo, gênero e sexualidade. 9. ed. Petrópolis, RJ: Vozes.

Machado, T. S., Bracht, V., de Almeida Faria, B., Moraes, C., Almeida, U., \& Almeida, F. Q. (2010). As práticas de desinvestimento pedagógico na Educação Física escolar. Movimento (ESEFID/UFRGS), 16(2), 129-147. Recuperado de https://www.seer.ufrgs.br/Movimento/article/view/10495/8924

Marconi, M. D. A., \& Lakatos, E. M. (2010). Metodologia cientifica. 7 ed. São Paulo: Atlas.

Maroun, K. (2015). Ginástica Geral e Educação Física Escolar: uma possibilidade de intervenção pautada na diversidade cultural. Revista Contemporânea de Educação, 10(19), 40-54.

Meneghetti, F. K. (2011). O que é um ensaio-teórico?. Revista de administração contemporânea, 15(2), 320-332. Recuperado de https://www.scielo.br/j/rac/a/4mNCY5D6rmRDPWXtrQQMyGN/?lang=pt

Miskolci, R. (2007). A Teoria Queer e a Questão das Diferenças: por uma analítica da normalização. In Congresso de leitura do Brasil (Vol. 16, pp. 10-12). Recuperado de http://alb.org.br/arquivomorto/edicoes_anteriores/anais 16/prog_pdf/prog03_01.pdf

Oliveira, N. R. C., \& de Lourdes, L. F. C. (2004). Ginástica geral na escola: uma proposta metodológica. Pensar a prática, 7(2), 221-230. Recuperado de https://www.revistas.ufg.br/fef/article/download/97/2352 ?inline=1

Oliveira, M. S., \& Nunomura, M. (2012). A produção histórica em ginástica e a constituição desse campo de conhecimento na atualidade. Conexóes, 10, 80-97. Recuperado de https://periodicos.sbu.unicamp.br/ojs/index .php/conexoes/article/view/8637663

Pereira Filho, E. (2005). Educação Física: limites da formação e exercício profissional. Formação profissional em educação física e o mundo do trabalho. In: Figueiredo, Z. C. C. (Eds). Formação profissional em educação física e mundo do trabalho. Vitória, ES: Gráfica da Faculdade Salesiana.

Preciado, B. (2011). Multidões queer: notas para uma política dos "anormais". Revista Estudos Feministas, 19(1), 11-20. Recuperado de https://www.scielo.br/scielo.php?pid=S0104-026X2011000100002\&script=sci_abstract\&tln $\mathrm{g}=\mathrm{es}$

Scott, J. W. (2005). O enigma da igualdade. Revista estudos feministas, 13(1), 11-30. 
Silva, R. H. D. R., Sousa, S. B., \& Vidal, M. H. C. (2008). Dilemas eperspectivas da educação física diante do paradigma da inclusão. Recuperado de https://www.revistas.ufg.br/fef/article/view/1793/4089

Souza, E. P. M. D. (1997). Ginástica geral: uma área do conhecimento da educação física. Recuperado de http://repos itorio.unicamp.br/handle/REPOSIP/275311

Spolaor, G. da C., \& Nunes, M. L. F. (2020). Rola bola: dispositivo que produz guetos culturais. Revista Brasileira de Educação Fisica e Esporte, 34(4), 623-637. https://doi.org/10.11606/1807-5509202000040623

Taffarel, C. Z. (2016). Pedagogia Histórico-Crítica e Metodologia de Ensino Crítico-Superadora da Educação Física: nexos e determinações. Nuances: estudos sobre Educação, 27(1), 5-23. Recuperado de https://revista.fct.unesp.b $\mathrm{r} /$ index.php/Nuances/article/view/3962

Toledo, E. de, \& Silva, P. C. da C. (2020). A Ginástica Para Todos e suas Territorialidades. Corpoconsciência, 24(1), 71-82. Recuperado de https://periodicoscientificos.ufmt.br/ojs/index.php/corpoconsciencia/article/view/100 92 